\title{
Association between Depression and HIV Treatment Outcomes in a US Military Population with HIV Infection
}

\author{
Brandon Carney \\ Colton Daniel \\ Xiaohe Xu \\ Thankam Sunil \\ Anuradha Ganesan \\ Jason Blaylock \\ Karl Kronmann \\ Christina Schofield \\ Tahaniyat Lalani \\ Brian Agan \\ Jason Okulicz ( $\square$ jason.f.okulicz.mil@mail.mil )
}

Short report

Keywords: HIV, depression, adherence, antiretroviral therapy, viral load suppression

Posted Date: May 7th, 2020

DOI: https://doi.org/10.21203/rs.3.rs-25914/v1

License: (c) (i) This work is licensed under a Creative Commons Attribution 4.0 International License. Read Full License

Version of Record: A version of this preprint was published at Open Forum Infectious Diseases on October 1st, 2019. See the published version at https://doi.org/10.1093/ofid/ofz360.442. 


\section{Association between Depression and HIV Treatment Outcomes in a US Military Population with HIV Infection}

Brandon Carney ${ }^{\mathrm{a}}$, Colton Daniels ${ }^{\mathrm{b}}$, Xiaohe $\mathrm{Xu} \mathrm{PhD}^{\mathrm{b}}$, Thankam Sunil $\mathrm{PhD}^{\mathrm{c}}$, Anuradha

Ganesan, ${ }^{\mathrm{d}, \mathrm{e}, \mathrm{g}}$, Jason M. Blaylock ${ }^{\mathrm{e}}$, Karl C. Kronmann ${ }^{\mathrm{f}}$, Christina Schofield ${ }^{\mathrm{h}}$, Tahaniyat Lalani ${ }^{\mathrm{df}, \mathrm{f}, \mathrm{e}}$, Brian Agan, ${ }^{\mathrm{d}, \mathrm{g}}$, Jason F Okulicz ${ }^{\mathrm{a}}$

${ }^{a}$ Brooke Army Medical Center

${ }^{\mathrm{b}}$ Department of Sociology, University of Texas at San Antonio

'Institute for Health Disparities Research, University of Texas at San Antonio

${ }^{\mathrm{d} I n f e c t i o u s ~ D i s e a s e ~ C l i n i c a l ~ R e s e a r c h ~ P r o g r a m, ~ D e p a r t m e n t ~ o f ~ P r e v e n t i v e ~ M e d i c i n e, ~ U n i f o r m e d ~}$ Services University of the Health Sciences, Bethesda, MD

${ }^{\text {e}}$ Walter Reed National Military Medical Center, Bethesda, MD

${ }^{\mathrm{f} N a v a l}$ Medical Center, Portsmouth, VA

${ }^{g}$ Henry M. Jackson Foundation for the Advancement of Military Medicine, Inc., Bethesda, MD

${ }^{\text {h}}$ Madigan Army Medical Center, Joint Base Lewis-McChord, WA

Corresponding author: Jason F. Okulicz, MD, San Antonio Military Medical Center 3551

Roger Brooke Drive, Fort Sam Houston, TX 78234-6200; Phone: (210) 916-5554; Fax (210)

916-5900; Email: jason.f.okulicz.mil@ mail.mil

\section{Abstract:}

Background: Depression is common among HIV-infected individuals and may contribute to suboptimal adherence to antiretroviral therapy (ART) and subsequent inability to attain viral load 
(VL) suppression. We evaluated longitudinal HIV treatment outcomes in US Military HIV Natural History Study (NHS) participants with depression.

Methods: Male NHS participants with available ICD-9 data for mental health diagnoses, Center for Epidemiological Studies Depression (CES-D) measures, and self-reported adherence (SRA) were included. ART use was defined as ART initiation between 2006-2010, with follow-up through 2015. SRA was defined as taking $\geq 95 \%$ of ART doses and continuous ART was defined as longitudinal ART use with gaps $<30$ days. Continuous VL suppression was defined as maintaining VLs $<200 \mathrm{c} / \mathrm{mL}$ on ART. To analyze the association between depression and HIV treatment outcomes, latent class analysis was used to create classes of depression trajectories: low depression (LD), recent onset depression (ROD) and high Depression (HD).

Results: Participants had a mean age of $32( \pm 8.3)$ years at HIV diagnosis, and similar proportions were Caucasian (44.3\%) or African American (40.8\%). Overall, older participants at HIV diagnosis had greater odds of having 95\% SRA (OR 1.06, 95\% CI 1.02-1.12), and African Americans had lower odds (OR 0.41, 95\% CI 0.22-0.76) compared to Caucasians (OR 1.49, 95\% CI 0.52-4.28). However, there was no difference in SRA by depression trajectory. Participants with HD had a trend towards taking ART continuously (OR 1.75, 95\% CI 0.99-3.09), and those with ROD had significantly higher odds of virologic failure (OR 0.58, 95\% CI 0.38-0.91).

Conclusions: Although there was no observed association between depression and SRA, participants with ROD had lower odds of attaining the HIV treatment goal of VL suppression. Continued efforts to identify and aggressively manage mental health disorders is important to success along the HIV care continuum.

Key Words: HIV; depression; adherence; antiretroviral therapy; viral load suppression 


\section{Introduction:}

Adherence to antiretroviral therapy (ART) is essential for the achievement and long-term maintenance of viral suppression in people living with HIV (PLWH). Durable viral suppression has many benefits including immune reconstitution, reduced risk of AIDS and prevention of onward transmission to sex partners (Rodger et al, 2016; Del Ramero J et al 2010). However, concurrent mental health diagnoses such as depression may negatively influence adherence to ART, resulting in failed viral suppression. Major depressive disorder has been shown to be more prevalent in PLWH compared to those without HIV infection (van Coppenhagen, B \& Duvenage, HS, 2019). A previous study reported that treatment-naïve patients with mental health disorders had slower rates of virologic suppression after ART initiation (Pence et al 2007).

The potential impact of depression on ART adherence has been evaluated in previous studies. For example, one study performed cross-sectional assessments of adherence and demonstrated greater odds of $<80 \%$ ART adherence among HIV infected individuals diagnosed with depression compared to those without depression (Tiffany CC et al 2019).

Another cross-sectional analysis from 2011-2014 in Chicago looked into multiple psychosocial conditions to include depression and anxiety and their relation to adherence (described as “syndemic"). Controlling for demographics and treatment factors, symptoms of depression were present in $38 \%$ of participants; and the likelihood of ART adherence decreased with the number of syndemic conditions included for analysis as did the odds of VL suppression. While interventions to address these co-morbid psychosocial conditions have been recommended, there is limited understanding of the specific relationship between clinical depression and ART adherence. Furthermore, the cross-sectional design of these prior studies 
limits the ability to substantiate links between treatment adherence/viral load suppression and depression among HIV infected persons.

We previously analyzed the relationship between longitudinal depression trajectories and sexual risk behaviors in US Military HIV Natural History Study (NHS), observing that participants with depression were less likely to use condoms and more likely to have sex with multiple partners (Carney et al 2019). The current analysis used the same longitudinal depression trajectories to further understand the potential impact of depression on HIV treatment outcomes.

\section{Methods:}

The NHS is a prospective observational cohort of HIV-infected active duty military personnel and beneficiaries. All participants were at least 18 years of age and provided written informed consent for this IRB-approved study. Male NHS participants were included who met criteria for available mental health diagnosis data, self-reported adherence (SRA) and ART use ( $\mathrm{n}=549)$. ART use was defined as ART initiation between 2006-2010, with follow-up through 2015. SRA was defined as taking $\geq 95 \%$ of ART doses and continuous ART was defined as longitudinal ART use with gaps $<30$ days. Continuous VL suppression was defined as maintaining VLs $<200 \mathrm{c} / \mathrm{mL}$ on ART over the same time period.

Self-reported Center for Epidemiological Studies Depression (CES-D) measures and ICD-9 codes for depression collected from 2006-2010 were evaluated with self-reported depressive symptoms from 2014-2015 as previously described (Carney et al 2019). Using a cutoff score of 16 to identify respondents at risk for clinical depression, the 20-item CES-D 
scores from 2006 (time period 1), 2007-08 (time period 2), and 2009 (time period 3), respectively, were coded such that 1 represented 16 or higher (at risk for clinical depression) and 0 indicating below 16 (less risk). The cutoff value of 16 was based on recommendations designated by the American Psychological Association (AERA). For the self-reported days of depression, participants were asked, "Thinking about your mental health, which includes stress, depression, and problems with emotions, for how many days during the past 30 days was your mental health not good?" Responses were coded into 1 being 1 or more days (at risk for clinical depression) and 0 indicating 0 days (no risk). These measures represent time periods 4 and 5 (2014-2015).

To utilize these self-reported depressive symptoms over the five time periods, Latent class analysis (LCA) was conducted to identify and categorize unmeasured, longitudinal depression trajectories rather than static group membership. LCA results revealed 3 trajectories: High Depression (HD; coded diagnosis for depression or CES-D score of 1 indicating higher risk of depression), recent onset depression (ROD; depressive symptoms present in periods 4 and 5 only), and low depression (LD; CES-D score of 0 indicated less depression risk). Sociodemographic characteristics were used as control measures. The 3 depression trajectories were further dummy-coded with LD serving as the reference for multivariate statistical modeling. The LCA was performed using MPlus and all other statistical analyses were conducted using Stata.

\section{Results:}

The mean age at HIV diagnosis for the 549 participants included in this study was 32 years, and similar proportions were Caucasian (44\%) and African American (41\%; Table 1). Participants had a mean CD4 count at HIV diagnosis of $502( \pm 246)$ cells $/ \mu \mathrm{L}$ and mean VL of 
$4.3 \log _{10}( \pm 0.9)$ copies $/ \mathrm{mL}$. The mean time from HIV diagnosis to ART initiation was $5.3( \pm 4.8)$ years due to CD4-based thresholds for initiating ART at the time of this study. For depression outcomes, $90 \%$ had a high risk CES-D score $(\geq 16)$ as opposed to having a coded diagnosis of depression. LCA for the CES-D and self-reported depressive symptoms categorized participants as $\operatorname{LD}(\mathrm{n}=326,59.4 \%)$, ROD $(\mathrm{n}=137,25 \%)$, and $\mathrm{HD}(\mathrm{n}=86,15.7 \%)$.

Overall, participants with increased age at HIV diagnosis (per one year) had higher odds of having 95\% SRA (OR 1.06, 95\% CI 1.02-1.12) while African Americans had significantly lower odds in our study (OR 0.41, 95\% CI 0.22-0.76) (Table 2). Individuals with ROD or HD did not demonstrate significant differences in SRA.

Participants with a CD4 count $\geq 500$ cells/uL at HIV diagnosis had higher odds of increased delay from HIV diagnosis to starting ART (OR 5.22, 95\% CI 3.45-7.89). This finding is likely due to the CD4 count thresholds from which to start therapy based on existing guidelines at that point in time. No significant association was found with age at HIV diagnosis or race for delay in starting ART.

Those with HD demonstrated a trend towards taking ART continuously (OR 1.75, 95\% CI 0.99-3.09), but not those with ROD (OR 1.28, 95\% CI 0.82-2.0). Other variables did not show statistical significance for continuous ART. Participants with ROD $(0.58,95 \%$ CI 0.38 0.91) had significantly lower odds of continuous VL suppression whereas no difference was observed for HD participants (OR 1.15, 95\% CI 0.65-2.06).

\section{Discussion:}

Analysis of different variables to include ART adherence and VL suppression among HIV-infected persons with a coded diagnosis of depression or self-reported data from the NHS cohort demonstrated that mental health comorbidities may influence these important elements of 
longitudinal HIV disease management. Historically, for ART to be most effective in preventing HIV virologic failure, ART adherence of $95 \%$ or greater is strongly recommended (Davies et al 2006) as was investigated for our current study. While the necessary adherence rate for sustained VL suppression likely varies among different classes and combinations of agents included in ART regimens, a high adherence goal is necessary given the intricacies of some ART regimens and the increased morbidity/mortality seen with suboptimal adherence (Gordan et al 2015). In our study, increased age at HIV diagnosis per one year was associated with better adherence to ART. This reporting of age as a determinant for adherence has been published elsewhere, citing better medication adherence in older individuals ( $>35$ years) compared with younger patients (Alemu et al 2011). Lower age as an independent risk factor for virologic failure has also been appreciated within our NHS cohort in prior literature looking at persistent low-level viremia and virologic failure (Joya et al 2019). Lower adherence in younger individuals may be related to more significant socioeconomic conditions as compared to older individuals or having less experience in interacting with the health care system (Watt et al 2010).

Lower adherence was observed in African Americans in our study. Young African American males may be less likely than Caucasian individuals to receive adequate mental health care secondary to economic, social or demographic barriers (Whitely et al 2014). Such perceived barriers may result in higher levels of healthcare mistrust than other racial groups, especially in the setting of concurrent psychosocial stressors as previously studied in this specific population (Heestermans et al 2016). Both measured and unmeasured factors may contribute to differences in adherence and warrants further study in our cohort.

Another variable assessed was documented adherence to ART over time. Participants in our study having HD showed a trend towards taking ART continuously, defined as gaps in ART 
compliance. While this result wasn't statistically significant for our cohort and may seem contrary to other study findings, such an association has been discussed in previous literature. In a cross-sectional prospective survey among $300 \mathrm{HIV}$-infected adults on ART in Botswana, an 87 question survey to include graded questions about depression was explored in relation to adherence (European Quality of Life instrument). Of these participants, 21\% had "severe depression," and while depression was found to be a predictor of poor adherence rates $(\mathrm{p}<0.02)$, adherence rates were poorest among those just starting ART, most notably within 1-6 months of starting compared to those on ART for > 12 months (Do et al 2010). This may be related to side effects or other factors not related to depression. More notably, a meta-analysis looking into depression and HIV treatment interventions found that greater improvements in adherence were found in individuals with more severe depression, using instruments to include CES-D scale measures that were used in our study. It is possible those with classification of more severe depression may perceive a greater opportunity for improvement in both HIV and depression management (Sin and DiMatteo, 2015).

Additionally, participants with ROD had significantly lower odds of achieving viral load suppression compared to those with HD. Many studies have evaluated the effect of depression on virologic response to ART with significant associations identified, even after controlling for adherence (Hartzell et al 2008). In a study of 198 ART-naïve patients initiating therapy for whom a previously validated model to predict psychiatric illness was employed, patients with such a projected diagnosis were slower to reach VL suppression (AHR 1.2, CI: 1.06-1.4), a result that may be attributable to adherence or loss of follow up ( (Pence et al 2007).

One limitation of this study is that all types of mental health data were not available throughout the study period. The particular diction within ICD-9 codes apropos distinguishing 
recurrent depression versus single episode depression for diagnosis is not always established. Another limitation is self-reported adherence as this is subject to social desirability bias. Additionally, our findings may not be generalizable to women as only males were included in this analysis. Furthermore, it would be reasonable to incorporate the number of participants undergoing active treatment for depression into future studies as this variable was not included in our analysis.

The relationship between depression and medication adherence among HIV-infected people to attain viral load suppression is complex. The marked improvements in ART have afforded PLWH an opportunity to live significantly longer and healthier lives than ever before. However, such benefits of ART depend on an individual's ability to adhere to daily medications, which can pose a challenge in those with comorbid mental health diagnoses such as depression. Improved identification and management of concurrent mood disorders are very important in optimizing ART adherence among HIV-infected persons.

\section{Declarations}

\section{Funding:}

This study was conducted by the Infectious Disease Clinical Research Program (IDCRP), a Department of Defense (DoD) program executed by the Uniformed Services University of the Health Sciences (USUHS) through a cooperative agreement with The Henry M. Jackson Foundation for the Advancement of Military Medicine, Inc. (HJF). This project has been funded in whole, or in part, with federal funds from the National Institute of Allergy and Infectious Diseases, National Institutes of Health (NIH), under Inter-Agency Agreement (Y1-AI-5072).

The authors have no financial disclosures to report.

\section{Disclaimer:}


The authors have no conflicts of interest to disclose. The view(s) expressed herein are those of the author(s) and do not reflect the official policy or position of Brooke Army Medical Center, Walter Reed National Military Medical Center, Naval Medical Center Portsmouth, Madigan Army Medical Center Uniformed Services University of the Health Sciences (USU), the Henry M. Jackson Foundation for the Advancement of Military Medicine, Inc. (HJF), the U.S. Army Medical Department, the U.S. Army Office of the Surgeon General, the Department of the Army, the Department of the Air Force and Department of Defense or the U.S. Government. Mention of trade names, commercial products, or organizations does not imply endorsement by the U.S. Government.

The investigators have adhered to the policies for protection of human subjects as prescribed in 45CRF46.

Some of the authors of this work are military service members or employees of the United States Government. This work was prepared as part of their official duties. Title 17 U.S.C. $\S 105$ provides that 'Copyright protection under this title is not available for any work of the United

States Government'. Title 17 U.S.C. $§ 101$ defines a U.S. Government work as a work prepared by a military service member or employee of the U.S. Government as part of that person's official duties.

\section{Competing interests}

The authors declare that they have no competing interests.

\section{Consent for publication}

This study is IRB approved and full complete consent was obtained.

\section{Ethics approval and consent to participate}


This study is IRB approved and full complete consent was obtained.

\section{Acknowledgements:}

This study IDCRP-000-03 was supported by the Infectious Disease Clinical Research Program (IDCRP), a Department of Defense (DoD) program executed through the Uniformed Services University of the Health Sciences (USUHS). This project has been funded in whole, or in part, with federal funds from the National Institute of Allergy and Infectious Diseases, National Institutes of Health (NIH), under Inter-Agency Agreement Y1-AI-5072.

\section{References:}

1. American Educational Research Association, American Psychological Association, \& National Council of Measurement in Education. (1999). Standards for educational and psychological testing. Washington, DC. American Educational Research Association. Retrieved from http://www.apa.org/science/programs/testing/standards.aspx

2. Centers for Disease Control and Prevention (CDC). HIV/AIDS: Basic Statistics Atlanta, GA; 2019. https://www.cdc.gov/hiv/basics/statistics.html.

3. van Coppenhagen B, Duvenage HS. Prevalence of depression in people living with HIV and AIDS at the Kalafong Provincial Tertiary Hospital Antiretroviral Clinic. S Afr J Psychiatr. 2019; doi:10.4102/sajpsychiatry.v25i0.1175.

4. Davies G, Koenig LJ, Stratford D, Palmore M, Bush T, Golde M, Malatino E, ToddTurner M, Ellerbrock TV. Overview and implementation of an intervention to prevent adherence failure among HIV-infected adults initiating antiretroviral therapy: lessons learned from Project HEART. AIDS Care. 2006 Nov; 18(8):895-903. 
5. Del RJ, Castilla J, Hernando V, Rodriguez C, Garcia S. Combined antiretroviral treatment and heterosexual transmission of HIV-1: cross sectional and prospective cohort study. BMJ 2010;340:c2205.

6. Do NT, Phiri K, Bussmann H, Gaolathe T, Marlink RG, Wester CW. Psychosocial factors affecting medication adherence among HIV-1 infected adults receiving combination antiretroviral therapy (cART) in Botswana. AIDS Res Hum Retroviruses. 2010; 26(6):685-691. doi:10.1089/aid.2009.0222.

7. Glynn TR, Safren SA, Carrico AW, Mendez NA, Duthely LM, Dale SK, Jones DL, Feaster DJ, Rodriguez AE. High Levels of Syndemics and Their Association with Adherence, Viral Non-suppression, and Biobehavioral Transmission Risk in Miami, a U.S. City with an HIV/AIDS Epidemic. AIDS and Behavior. 07August 2019.

8. Gross IM, Hosek S, Richards MH, Fernandez MI. Predictors and Profiles of Antiretroviral Therapy Adherence Among African American Adolescents and Young Adult Males Living with HIV. AIDS Patient Care STDS. 2016; 30(7):324-338. doi:10.1089/apc.2015.0351

9. Heestermans T, Browne JL, Aitken SC, Vervoort SC, Klipstein-Grobusch K. Determinants of adherence to antiretroviral therapy among HIV-positive adults in subSaharan Africa: a systematic review. BMJ Glob Health. 2016. doi:10.1136/bmjgh-2016000125

10. Joya C, Won SH, Schofield C, et al. Persistent Low-level Viremia While on Antiretroviral Therapy Is an Independent Risk Factor for Virologic Failure. Clin Infect Dis. 2019;69(12):2145-2152. doi:10.1093/cid/ciz129 
11. Kahler CW, Wray TB, Pantalone DW, Kruis RD, Mastroleo NR, Monti PM, \& Mayer KH. Daily associations between alcohol use and unprotected anal sex among heavy drinking HIV-positive men who have sex with men. AIDS Behav, March 2015. 19(3), $422-430$.

12. Kalichman, SC \& Weinhardt L. Negative affect and sexual risk behavior: Comment on Crepaz and Marks. Health Psychology, 2001. 20, 300-301.

13. Kuhns M, Hotton AL, Garofalo R, Muldoon AL, Jaffe K., Bouris A., Schneider, J. (2016). An Index of Multiple Psychosocial, Syndemic Conditions Is Associated with Antiretroviral Medication Adherence Among HIV-Positive Youth. AIDS patient care and STDs, 2016. 30(4), 185-192. doi:10.1089/apc.2015.0328.

14. Madhura SR, Ting H, Sabina G, Hilary T, Mahomed-Yunus M, Connie C, Paul KD. Depression and Anxiety as Risk Factors for Delayed Care-Seeking Behavior in Human Immunodeficiency Virus-Infected Individuals in South Africa, Clinical Infectious Diseases, Volume 67, Issue 9, 1 November 2018, Pages 1411-1418, https://doi.org/10.1093/cid/ciy309.

15. Memiah P, Shumba C Etienne-Mesubi. The effect of depressive symptoms and CD4 count on adherence to highly active antiretroviral therapy in sub-Saharan Africa. $J$ Int Assoc Provid AIDS Care 2013; 13:346-52.

16. Mirza RA, Eick-Cost A, \& Otto JL. The risk of mental health disorders among U.S. military personnel infected with HIV, active component, U.S. Armed Forces, 2000-2011. MSMR. 2012 May: 19(5):10-3. 
17. O’Cleirigh C., Magidson JF, Skeer M., Mayer KH \& Safren SA. Prevalence of psychiatric and substance abuse symptomatology among HIV-infected gay and bisexual men in HIV primary care. HHS Public Access, 2015. 56(5), 470-478.

18. Pence BW, Miller WC, Gaynes BN, Eron JJ Jr. Psychiatric illness and virologic response in patients initiating highly active antiretroviral therapy. J Acuir Immune Deficiency Syndrome. 2007 Feb 1; 44 (2): 159-66.

19. Rodger AJ et al for the PARTNER study group. Sexual activity without condoms and risk of HIV transmission in serodifferent couples when the HIV-positive partner is using suppressive antiretroviral therapy. JAMA, 2016;316(2):1-11

20. Sikkema KJ, Watt MH, Drabkin AS, Meade CS, Hansen NB \& Pence BW. Mental health treatment to reduce HIV transmission risk behavior: A positive prevention model. AIDS \& Behavior, 2010. 14, 252-262.

21. Sin NL, DiMatteo MR. Depression treatment enhances adherence to antiretroviral therapy: a meta-analysis. Ann Behav Med. 2014 ;47(3):259-269. doi:10.1007/s12160013-9559-6

22. Surkan PJ, Li Y \& Jacobson LP. Unsafe sexual behavior among gay/bisexual men in the era of combination antiretroviral therapy (cART). AIDS Behav, 2016. doi:10.1007/s10461-016-1614-4.

23. Wang N, Wang S, Qian HZ, Ruan Y, Amico KR, Vermund SH, Yin L, Qiu X \& Zheng S. Negative associations between general self-efficacy and anxiety/depression among newly HIV-diagnosed men who have sex with men in Beijing, China. AIDS Care. 2019 May. doi: 10.1080/09540121.2018.1549721. 
24. Watt MH, Maman S, Golin CE, et al. Factors associated with self-reported adherence to antiretroviral therapy in a Tanzanian setting. AIDS Care. 2010; 22(3):381-389. doi:10.1080/09540120903193708.

25. Whiteley LB, Brown LK, Swenson R, Kapogiannis BG, Harper GW. Disparities in mental health care among HIV-infected youth. J Int Assoc Provid AIDS Care. 2014 JanFeb; 13(1):29-34.

26. Wilson PA, Stadler G, Boone MR \& Bolger N. Fluctuations in depression and well-being are associated with sexual risk episodes among HIV-positive men. Health Psychology, 2014. 33(7).

\begin{tabular}{|l|c|}
\hline \multicolumn{2}{|c|}{ Table 1. Characteristics of NHS participants } \\
\hline Characteristic & Number (n) or Mean ( \pm SD) \\
\hline Number, $\mathrm{n}$ & 549 \\
\hline Age & $52.1(10)$ \\
\hline Mean age at HIV diagnosis (years) & $32.7(8.3)$ \\
\hline Mean CD4 count at HIV diagnosis (cells/ $\mu \mathrm{L})$ & $502.8(246.1)$ \\
\hline Mean viral load at HIV diagnosis $\left(\log _{10}\right.$ copies $\left./ \mathrm{mL}\right)$ & $4.3(0.9)$ \\
\hline Mean viral load at ART (log ${ }_{10}$ copies $\left./ \mathrm{mL}\right)$ & $4.3(0.9)$ \\
\hline Time from HIV diagnosis to ART start (years) & $5.3(4.8)$ \\
\hline Mean time from HIV negative to seroconversion (years) & $2.0(1.9)$ \\
\hline & \\
\hline Independent Variables & \\
\hline Depression Classes & 326 \\
\hline Low Depression Throughout (reference) & 137 \\
\hline Recent Onset Depression & 86 \\
\hline High Depression Throughout & 243 \\
\hline Race & 224 \\
\hline Caucasian & 82 \\
\hline African-American & \\
\hline Other & \\
\hline
\end{tabular}

${ }^{1}$ Some patients did not have information in their medical records on CD4 cell count at HIV diagnosis (9\%) or VL at ART start (8\%). 


\begin{tabular}{|c|c|c|c|}
\hline \multicolumn{4}{|c|}{ Table 2. Association between depression and HIV treatment outcomes } \\
\hline \multicolumn{4}{|c|}{ Self-Reported Adherence $(\geq 95 \%$ of ART doses) } \\
\hline $\begin{array}{l}\text { Variables } \\
\end{array}$ & OR & $95 \% \mathrm{CI}$ & P-value \\
\hline Age at HIV diagnosis (per 1 year increase) & 1.06 & $1.02-1.12$ & 0.004 \\
\hline Race & & & 0.003 \\
\hline African American & 0.41 & $0.22-0.76$ & 0.005 \\
\hline Caucasian (reference) & 1.49 & $0.52-4.28$ & 0.459 \\
\hline Recent Onset Depression & 0.59 & $0.32-1.11$ & 0.101 \\
\hline High Depression & 0.61 & $0.29-1.27$ & 0.187 \\
\hline CD4 count at HIV Diagnosis $\geq 500$ cells/uL & 0.81 & $0.46-1.41$ & 0.451 \\
\hline \multicolumn{4}{|c|}{ Delay from HIV Diagnosis to ART Start } \\
\hline Variables & OR & $95 \% \mathrm{CI}$ & P-value \\
\hline Age at HIV diagnosis & 0.91 & $0.87-0.96$ & 0.001 \\
\hline Race & & & 0.273 \\
\hline African American & 1.28 & $0.82-2.00$ & 0.273 \\
\hline Caucasian (reference) & 0.69 & $0.36-1.33$ & 0.385 \\
\hline Recent Onset Depression & 0.92 & $0.56-1.49$ & 0.818 \\
\hline High Depression & 1.17 & $0.66-2.01$ & 0.603 \\
\hline CD4 count at HIV Diagnosis $\geq 500$ cells/uL & 5.22 & $3.45-7.89$ & 0.001 \\
\hline \multicolumn{4}{|c|}{ Continuous ART (Break <30 days) } \\
\hline Variables & OR & $95 \% \mathrm{CI}$ & P-value \\
\hline Age at HIV diagnosis & 0.1 & $0.96-1.01$ & 0.218 \\
\hline Race & & & 0.671 \\
\hline African American & 1 & $0.67-1.51$ & 0.988 \\
\hline Caucasian (reference) & 1.29 & $0.72-2.31$ & 0.401 \\
\hline Recent Onset Depression & 1.28 & $0.82-2$ & 0.272 \\
\hline High Depression & 1.75 & $0.99-3.09$ & 0.057 \\
\hline CD4 count at HIV Diagnosis $\geq 500$ & 1.07 & $0.73-1.57$ & 0.726 \\
\hline \multicolumn{4}{|c|}{ Continuous Viral Load Suppression $(<200 \mathrm{c} / \mathrm{mL})$} \\
\hline Variables & OR & $95 \% \mathrm{CI}$ & P-value \\
\hline Age at HIV diagnosis & 1.01 & $0.99-1.03$ & 0.451 \\
\hline Race & & & 0.43 \\
\hline African American & 0.92 & $0.6-1.4$ & 0.693 \\
\hline Caucasian (reference) & 1.37 & $0.74-2.53$ & 0.312 \\
\hline Recent Onset Depression & 0.58 & $0.38-0.91$ & 0.017 \\
\hline High Depression & 1.15 & $0.65-2.06$ & 0.63 \\
\hline CD4 count at HIV Diagnosis $\geq 500$ & 1.15 & $0.77-1.71$ & 0.495 \\
\hline
\end{tabular}

